\title{
La aplicación constitucional preferente del derecho internacional
}

\author{
Priority constitutional application \\ of international law
}

Eladio Arroyo Lara* y Luis V. Pérez Gil**

\section{Resumen}

El presente ensayo tiene como finalidad principal exponer la tesis de la aplicación constitucional preferente del Derecho internacional respecto del Derecho interno, acudiendo a una interpretación metódica y sistemática de la Constitución española de 1978. Pero esta cualificación no es privativa del ordenamiento constitucional español. Sistemas como el alemán anterior a la reunificación, tanto de la República Federal como de la República Democrática, imponían la equivalencia del Derecho internacional general respecto a los ordenamientos internos y, en su caso, la prevalencia del Derecho internacional convencional. Es pertinente citar, aunque pertenezca a un conjunto jurídico distinto, el caso del common law inglés y con eso queremos señalar que la Constitución española no es un supuesto aislado y extraño entre espacios jurídicos homogéneos, sino que sigue una tradición común a casi todos los sistemas jurídicos actuales.

Palabras clave: Relaciones entre Derecho internacional y Derecho interno; aplicación preferente del Derecho internacional; Derecho de los tratados; jerarquía normativa.

* Catedrático de Derecho Internacional Público. <earroyo@ull.es>.

** Catedrático de Derecho Internacional Público, Universidad de La Laguna, España. <loperezg@ull.es>.

Artículo recibido el 7 de febrero de 2009. Aceptado el 19 de mayo de 2009. 


\section{Abstract}

The main purpose of this essay is to sustain the thesis of the priority application of international law over domestic law through a methodical and systematic interpretation of the Spanish Constitution of 1978. This qualification is not exclusive of the Spanish case. Constitutional systems such as that applicable in Germany before reunification, both in the Federal and in the Democratic Republic established the equivalence of general international law and domestic laws and, as the case may be, the prevalence of conventional international law. Although pertaining to a different legal system, mention should be made of English common law, so as to point that the Spanish Constitution is not an isolated and unusual case among homogeneous legal spaces, but follows a tradition common to almost all present legal systems.

KeY wORDs: Relations between international law and municipal law; priority application of international law; Law of Treaties; hierarchy of norms. 
Eladio Arroyo y Luis Pérez • La aplicación constitucional preferente...

\section{INTRODUCCIÓN}

El resultado de las elecciones generales celebradas el 15 de junio de 1977 dio origen a un Poder Legislativo investido de una doble función: constituyente -pues el objetivo prioritario era la elaboración de una nueva Constitución- y de aprobación de las leyes ordinarias que la nueva situación política demandaba. El 27 de julio se designó con carácter provisional la Comisión Constitucional que se reunió el 1 de agosto para nombrar la ponencia encargada de redactar el anteproyecto de Constitución. Las sesiones comenzaron el 24 de agosto de 1977, publicándose el anteproyecto y los votos particulares de los ponentes el 5 de enero de 1978 . El informe de la ponencia se publicó el 17 de abril de 1978, con lo cual se dio inicio a los trámites en el Congreso de los Diputados y en el Senado, quedando formalmente aprobado el dictamen de la Comisión Mixta el 6 de noviembre de 1978. El texto constitucional se sometió a referéndum el 6 de diciembre de 1978 y fue aprobado por el $87.78 \%$ de los votos. La Constitución española fue sancionada por el Rey el 27 de diciembre y publicada dos días después en el Boletín Oficial del Estado.

Desde el inicio de los trabajos los ponentes constitucionales tenían claro que los artículos de la nueva Constitución dedicados al derecho internacional debían estar redactados en forma sencilla y concisa de modo da dar lugar al mínimo posible de interpretaciones. El que lo consiguieran o no es objeto de lo que sigue a continuación.
Tradicionalmente las leyes constitucionales españolas contenían preceptos que hacían referencia al derecho internacional, pero normalmente de forma muy vaga e imprecisa. Por ejemplo, el artículo 7 de la Constitución de 9 de diciembre de 1931 decía: «El Estado español acatará las normas universales del Derecho Internacional incorporándolas a su derecho positivo». Se trata de una declaración eminentemente voluntarista puesto que, en una interpretación literal, el Estado español declara que acata las normas universales, sin decir cuáles son y qué contenido tienen. Como consecuencia de ello, esas desconocidas normas universales debían incorporarse en el derecho positivo, sin decir cuándo ni cómo ${ }^{1}$. Este ejemplo es muy común en las legislaciones constitucionales de la época -como en la Constitución alemana de 1919- y solo posteriormente han incorporado mayor precisión en lo que es la esencia de la relación entre los dos ordenamientos, el interno y el internacional, que es, precisamente, cómo articulan su aplicabilidad las normas provenientes de los dos sistemas normativos ${ }^{2}$.

1 Véase Pérez Gil, Luis V. (2001): «Análisis de los principios constitucionales y las competencias en las relaciones exteriores en la Constitución española de diciembre de 1931", Revista Española de Derecho Constitucional 63, pp. 129-165.

2 Remitimos el estudio histórico que de Marín López, Antonio (1952): «El problemas de las relaciones entre el Derecho interno y el Derecho internacional en las Constituciones", Revista Española de Derecho Internacional 1, págs. 529-602. 
El derecho internacional tiene dos partes bien diferenciadas: el llamado derecho internacional general, compuesto de costumbres internacionales y principios generales del derecho y el derecho internacional convencional, que se compone esencialmente de los tratados internacionales ${ }^{3}$. Estas son las únicas fuentes de derecho internacional existentes, si excluimos el peculiar supuesto de los actos unilaterales, que son fuente de derecho de características muy especiales y que no conviene tratar aquí, entre otras cosas, porque la Constitución Española de 1978 -en adelante CE-no los menciona ${ }^{4}$.

Por lo que se refiere al derecho internacional general, existe alguna opinión, tan relevante como la del desaparecido profesor MIAJA DE LA Muela, que señaló, argumentándolo cuidadosamente, que el artículo 7 de la Constitución de diciembre de 1931 continuó en vigor pese a las Leyes Fundamentales del régimen del general Franco, puesto que no existía, y eso es cierto, contradicción alguna entre esa disposición y las normas posteriores ${ }^{5}$. Esto es así porque las costumbres internacionales generalmente reconocidas y los principios generales de derecho

3 Remitimos a la obra clásica de Verdross, Alfred (1974): Derecho Internacional Público, Madrid, Aguilar (5 ${ }^{\mathrm{a}}$ ed.), pp. 89130.

4 Para ello remitimos a la obra clásica de Suy, Eric (1962): Les actes juridiques unilatéraux en Droit international public, París, R. Pichon et R. Durand-Auzias.

5 Introducción al Derecho Internacional Público, Madrid, Internacional Ediciones Atlas (1968, 4ª ed.), pp. 220-221. pueden ser aplicados por los tribunales internos sin necesidad de norma alguna que lo autorice. En la escala normativa, las Constituciones en general no tienen por qué contener normas que autoricen la aplicación del derecho internacional general. Este automáticamente forma parte del derecho que deben aplicar los órganos judiciales puesto que la legislación interna debe admitir lo que la sociedad general de los Estados considera sus costumbres y sus principios generales. Ese Derecho Internacional general es el verdadero derecho común de todos los Estados, aplicable por sus tribunales sin más problemas que adecuarlo a su sistema judicial.

\section{EL DERECHO INTERNACIONAL GENERAL Y CONVENCIONAL EN la Constitución española de I 978}

En España, el primer borrador constitucional de 1977, nunca publicado como texto oficial, decía: "Las normas generales del Derecho Internacional tienen fuerza de ley en el ordenamiento interno", texto que no prosperó. Posteriormente, el senador Ollero intentó introducir una enmienda al esquema general que decía: «las normas generales del Derecho Internacional son parte integrante del ordenamiento jurídico interno", que tampoco fue aceptada ${ }^{6}$

Serrano Alberca, José Manuel (1985): «Artículo 93», en Garrido Falla,y otros.: Comentarios a la Constitución, Madrid, Civitas, pp. 1324-1332. 
Eladio Arroyo y Luis Pérez • La aplicación constitucional preferente...

-como era de esperar en una Comisión de constitucionalistas clásicos- pese a su rigor y claridad, pues hubiera evitado toda clase de conflictos normativos al equiparar el derecho internacional general con normas del derecho interno estatal.

En rigor, la CE no dice nada al respecto, excepto que entendamos que es innecesario, puesto que la recepción del derecho internacional general es automática; pero lo que no es automático es su aplicación. Esa distinción entre recepción y aplicación deja a salvo al poder judicial para aplicar o no el derecho internacional general, puesto que no hay norma que obligue ni, sobre todo, normas constitucionales que lo hagan. El valor que tiene, pues, el derecho internacional general es, simplemente, que es posible pero no obligatorio aplicarlo. Esta cuestión es de importancia extrema por cuanto se deja en manos del juez la elección de una norma de derecho internacional general que existe como norma aplicable sin necesidad de ulterior desarrollo.

La única referencia al derecho internacional general se encuentra en el artículo 96.1 de la CE, cuando afirma que los tratados no podrán ser derogados, modificados o suspendidos sino de acuerdo con las normas contenidas en el propio tratado o de acuerdo con las normas generales del derecho internacional. Si los tratados no pueden nunca ser derogados, modificados o suspendidos sino, en su caso, por una norma de derecho internacional general, es que este es susceptible de aplicarse para una función extraordinaria: la derogación de una norma proveniente de un tratado, que no puede ser derogada por ninguna otra de cualquier clase ${ }^{7}$. Esto, que es simple y sencillo porque de la interpretación literal no puede colegirse otra cosa, ha hecho que alguna vez los tribunales españoles hayan aplicado normas de derecho internacional general, como en la sentencia del Tribunal Supremo de 6 de marzo de 1982 sobre la afectación de las normas españolas referentes a la inmunidad de los Estados por la existencia de costumbres internacionales en la materia, o en la sentencia del Tribunal Supremo de 13 de junio de 1991 respecto del acceso de ciudadanos extranjeros a los tribunales ${ }^{8}$. En suma, la CE no dice más de lo que hemos expuesto, pero es indiferente que lo haga. El derecho internacional general es derecho interno a disposición del juez, si este cree que es aplicable.

En cuanto al derecho internacional convencional, que es el que surge de los

\footnotetext{
Véase Arroyo Lara, Eladio (1987): «Consideración sobre el alcance y contenido del artículo 96.1, «in fine» de la Constitución Española», Revista Española de Derecho Internacional 2, págs. 405-421.

8 Repertorio de Jurisprudencia Aranzadi 1365/1982 y 5286/1991 respectivamente. En el mismo sentido, las sentencias del Tribunal Constitucional 201/1992, de 14 de febrero de 1992 y 292/1994, de 27 de octubre de 1994, casi todas ellas referidas a la cuestión de la inmunidad estatal. Las sentencias del TC se encuentran disponibles en http://www.tribunalconstitucional.es/jurisprudencia/jurisprudencia. html y en http://www.boe.es/g/es/bases_datos/tc.php
} 
tratados, la cuestión es bien distinta. La CE sí trata de este derecho especial en los artículos 93 al 97, que trataremos a continuación, singularmente los artículos 93 y 96.

Debemos aclarar con carácter previo que ni el Jefe del Estado ni el Parlamento pueden legítimamente forzar la negociación de ningún tratado, pero la libertad del Gobierno tampoco es absoluta. La CE contiene preceptos que auspician la negociación y la conclusión, pero señala sus límites. Como parece lógico, el control del Parlamento, previo a la manifestación del consentimiento, es la mejor garantía, ya que según previene el artículo 66.2 de la CE, posee la facultad de vigilar la acción del Gobierno9. Lo que sí parece lógico es que la CE hubiese incluido un precepto que obligase al Gobierno a mantener al Parlamento informado de los pasos en la negociación del tratado, precepto que no existe.

¿Y qué dice la CE sobre los tratados internacionales? ¿Cuál es el lugar de los tratados en el derecho español?

Antes de entrar en ello, veamos, por pura lógica formal, cuál es el control constitucional anterior a la firma. Dos artículos de la CE, el 93 y el 94, se

9 Sobre este punto, véase García Morillo, Joaquín (1985): El control parlamentario del gobierno en el ordenamiento español, Madrid, Congreso de los Diputados; Montero Gibert, José Ramón y García Morillo, Joaquín (1984): El control parlamentario, Madrid, Tecnos; Remiro Brotóns, Antonio (1988): Politica exterior de defensa y control parlamentario, Madrid, Centro de Estudios Constitucionales. refieren al necesario control, cosa que es común a los sistemas de normas fundamentales en la sociedad internacional occidental. Del primero de ellos hablaremos extensamente más adelante; del segundo, el artículo 94, diremos que el sistema constitucional español es de los denominados «de lista», en otros términos, una serie de tratados que tienen un contenido material determinado precisan, para su correcta celebración, que el Parlamento la autorice. Los demás tratados, fuera del listado contenido en el artículo 94.1, no requieren autorización, pero su celebración deberá comunicarse al Legislativo. La lista de tratados que requieren autorización parlamentaria es concisa: tratados de carácter político -lo que quiera que sea eso, pues la calificación de "político» está abierta de forma casi infinita-, convenios de carácter militar de la clase que fueren, que afecten a la integridad territorial del Estado o a los derechos y deberes contenidos en el Título I de la propia $\mathrm{CE}$, los que impliquen obligaciones financieras para la Hacienda Pública y los que exijan la modificación o derogación de alguna ley o requieran medidas legislativas para ser ejecutados. Más acá o más allá de esa lista no se necesita autorización parlamentaria previa al consentimiento para obligarse internacionalmente ${ }^{10}$.

Si el Parlamento apreciase que el tratado a celebrar contenido alguna

10 Véase Pastor Ridruejo, José Antonio (2007): Curso de Derecho Internacional Público y Organizaciones Internacionales, Madrid, Tecnos (11ª ed.), pp. 97-104. 
Eladio Arroyo y Luis Pérez • La aplicación constitucional preferente...

disposición que afecte a la CE, deberá consultarse al Tribunal Constitucional -en adelante TC- y, en su caso y siempre que se desee, ha de reformarse la Constitución, según determina el artículo 95.

Como el sistema parlamentario necesita de un órgano que lo asesore sobre cuál es la vía o procedimiento correcto para celebrar un tratado sometido a su consideración ${ }^{11}$, requiere una calificación técnica previa y, por tanto, cabe preguntarse a quien corresponde calificar. Porque el Parlamento no tiene por qué saber si el tratado es inconstitucional, si no lo es pero necesita autorización parlamentaria por Ley Orgánica -artículo 93-, autorización simple -artículo 94.1- o ninguna, sino ser informado con posterioridad. Por eso, es esencial conocer el órgano que tiene asignada la función calificadora. En sentido amplio, «calificar» significa que antes de manifestar su consentimiento, el Gobierno ha de remitir el tratado para que determinados órganos facultados para ello indiquen cuál debe ser el procedimiento a seguir, bien el artículo 93, el 94.1 o el 94.2. También es calificar si el Gobierno aprecia libremente que el tratado que va a negociarse, en cualquiera de sus fases, puede ser susceptible de inconstitucionalidad. Para ello eleva requerimiento al órgano competente, en este caso el

11 Asunto del que se ocupó prontamente el profesor Remiro Brotóns, Antonio (1980): «La actuación parlamentaria en la conclusión de los tratados: el problema de la calificación", Revista Española de Derecho Internacional 1/3, pp. 123-142.
TC, que emite un juicio declarativo -como quiera que lo llame el propio TC, como veremos más adelante- sobre la cuestión. Esa función le corresponde al Gobierno, pero ayudado por el Consejo de Estado. Así, la Ley 3/1980, de 22 de abril, del Consejo de Estado -en adelante LOCE-, en su artículo 22.1 hace preceptivo el dictamen del Consejo sobre si un tratado determinado ha de someterse a la autorización del Parlamento $^{12}$. En nuestra opinión, lo único que hace esta disposición es entorpecer los trámites porque lo convierte en un proceso innecesario y lento, puesto que aun con dictamen, se mantiene abierto el conflicto de calificación entre el Gobierno y el Parlamento. No debe olvidarse que emitir un dictamen, y el término lo dice, es propiamente dar una opinión, un consejo, pero siempre no vinculante. A mayor abundamiento, el propio artículo 22 de la LOCE no dice que el Consejo tenga o deba informar sobre si la autorización debe articularse por medio de una Ley Orgánica o con el consentimiento simple.

La Orden Ministerial de 17 de febrero de 1992 dice que, previo al dictamen del Consejo de Estado, la Dirección General del Ministerio competente por razón de la materia, enviará todo el expediente a la Asesoría Jurídica In-

12 Véase Sánchez Patrón, José Manuel (2005): «La contribución del Consejo de Estado a la aplicación del artículo 93 de la Constitución Española", en Presente y futuro de la Constitución Española de 1978, Valencia, Universitat de Valencia/ Tirant lo Blanch, pp. 777-787. 
ternacional ${ }^{13}$. La Asesoría puede hacer, o tiene competencia para hacer, dos cosas. La primera, mediante procedimiento de urgencia, elevar directamente el tratado al Consejo de Ministros sin necesidad del preceptivo dictamen del Consejo de Estado, eso sí, por razones que «deberán justificarse». La segunda, la Asesoría de forma preceptiva informa sobre cuál ha de ser el trámite a seguir y ese informe lo remite al Consejo de Estado, de modo que quien verdaderamente dictamina es la asesoría Jurídica Internacional, anticipándose de hecho a la decisión del Consejo ${ }^{14}$. En realidad, esto significa eludir u omitir íntegramente lo previsto en la LOCE.

Esto lleva a concluir que existen dos "calificaciones»: una obligada, la del Consejo de Estado, y otra voluntaria, la del TC. Dependerá de si el Gobierno estima que existe violación de la constitucionalidad, porque el TC en ningún caso puede apreciar de oficio un texto que aún no conoce. Solo podrá apreciar el defecto ex post, no ex ante. Con ese andamiaje, el Parlamento ha de limitarse a aprobar o no un tratado que se le propone y enfrentar las consecuencias de un posible recurso de inconstitucionalidad.

13 La Asesoría Jurídica Internacional, dentro de la Subsecretaría, es el órgano asesor de todo el Ministerio de Asuntos Exteriores y de Cooperación en materia de Derecho Internacional.

14 El texto de la OM se encuentra disponible en http://www.maec.es/ca/Recopilación\%20de\%20Órdenes\%20circulares/ Paginas/3.173.aspx
LA VALIDEZ Y EFICACIA DE LOS

TRATADOS EN EL DERECHO

INTERNO ESPAÑOL

La recepción de una norma en derecho interno español se regula en el artículo 96.1 de la CE en concordancia con el artículo 1.5 del Título Preliminar del Código Civil -en adelante CC. El término «recepción» implica en sí un dualismo: se recibe en un ordenamiento lo que proviene de otro. Por un lado, el artículo 96.1 afirma que los tratados una vez publicados formarán parte del derecho interno, lo que significa, a sensu contrario, que antes de publicarse, no se integran, no forman parte de ese derecho. En justa correspondencia, el artículo 1.5 del CC dice que las normas contenidas en los tratados internacionales no formarán parte del derecho interno hasta tanto no se publiquen ${ }^{15}$.

En realidad, el sistema constitucional español es lo que se denomina un sistema monista moderado, en cuanto la recepción automática de los tratados en el derecho interno se produce una vez que el tratado entra en vigor internacionalmente ${ }^{16}$. En otros términos, la

15 Véase González Campos, Julio (1977): «Artículo 1.5 del nuevo Título Preliminar del Código Civil», en Comentarios a las reformas del Código Civil, Madrid, Tecnos, vol. I; Pastor Ridruejo (2007): Curso de Derecho Internacional Público y Organizaciones Internacionales, op. cit., pp. 175-181.

16 El problema de las relaciones entre el derecho internacional y el Derecho interno ha sido estudiado extensamente por la doctrina internacionalista. Para un exa- 
Eladio Arroyo y Luis Pérez • La aplicación constitucional preferente...

obligación es exigible desde el momento en que el tratado es internacionalmente válido. Si pensamos que la lectura literal de los artículos 96.1 de la CE y 1.5 del CC conduce a la interpretación de que los tratados no publicados no forman parte del Derecho interno -tesis abiertamente dualista- de todas las maneras se produciría la responsabilidad del Estado. La falta de publicación, en suma, no puede eximir a un Estado del cumplimiento de los tratados.

¿Cómo puede obviarse, entonces, el problema de la publicación? ¿Cuál es la auténtica función de esta? La publicación es, sin lugar a dudas, un acto material, algo extrínseco al propio tratado; publicar un tratado no significa que ese mero acto administrativo transforme nada menos que el derecho internacional en derecho interno. El efecto de la publicación es permitir la aplicación material del tratado, concederle la condición de oponibilidad. En nuestra opinión, el tratado es derecho interno desde que está válidamente celebrado y ha entrado en vigor internacionalmente, aunque no esté publicado. La pregunta razonable sería: ¿cómo puede un juez aplicar un tratado que no ha sido todavía publicado, más aún si se lo exige la propia CE y el CC? Si la Administración estatal no publica un tratado porque no lo desea, o sencillamente se retrasa

men de las diferentes escuelas remitimos a la obra de MARín López (1952): «El problema de las relaciones entre el derecho interno y el Derecho internacional en las Constituciones» (op. cit.) y la extensa bibliografía que allí se cita. en hacerlo, como es habitual, ¿qué ocurre con las situaciones existentes entre la entrada en vigor del tratado y la publicación? Los particulares, en su caso, afectados, ¿están indefensos? El formalismo positivista afirmaría: un juez no puede aplicar lo que ignora, es más, le está prohibido hacerlo y parece lógico que esta opinión sea prevalente. Pero, como decimos, la publicación es condición de aplicabilidad, no de validez. El tratado, desde el momento de su entrada en vigor, es derecho interno, pero no se puede aplicar hasta que se publique. Si el tratado impone obligaciones y concede derechos a los individuos y no se publica, por los motivos que fueren, puede abrirse una vía excepcional de reclamación ante los órganos estatales. Si concede derechos individuales y las personas físicas o jurídicas no pueden disfrutarlos por no estar publicado y si las disposiciones convencionales son «directamente aplicables» o self-executing, cabría recurrir ante la Administración por daños. Es responsabilidad de esta la publicación, pero no se debe olvidar que, de todas formas, todo tratado es, desde la fecha de su entrada en vigor, parte del derecho interno porque así lo ordena la misma $\mathrm{CE}^{17}$.

17 Arroyo Lara (1987): «Consideración sobre el alcance y contenido del artículo 96.1, «in fine» de la Constitución Española», op. cit., pp. 410-411. 


\section{LA JERARQUÍA DE LOS TRATADOS RESPECTO DE LAS NORMAS INTERNAS}

No es fácil, en una visión general, esclarecer el rango jerárquico de una norma contenida en un tratado que ya es derecho interno, respecto de las demás. La CE contiene dos preceptos ilustrativos, los artículos 95.1 y 96.1 .

El artículo 95.1 está previsto para los tratados que aún no se han incorporado al derecho interno. El Gobierno o cualquiera de las Cámaras del Legislativo pueden requerir al TC que se pronuncie sobre la existencia o no de contradicción entre la CE y las estipulaciones de un tratado cuyo texto esté fijado pero al que no se hubiese prestado todavía el consentimiento del Estado para obligarse internacionalmente. Una vez recibido el requerimiento el procedimiento se sustancia por la vía del artículo 78 de la Ley Orgánica del TC. El mismo Tribunal tuvo ocasión de pronunciarse sobre la naturaleza del requerimiento del artículo 95.2 en la Declaración de 1 de julio de 1992:

«(...) ha de comenzar por precisarse que lo que de nosotros puede solicitarse es una declaración, no un dictamen; una decisión, no una mera opinión fundada en Derecho. Este Tribunal no deja de serlo para transformarse ocasionalmente, por obra del requerimiento, en cuerpo consultivo. Lo que el requerimiento incorpora es, al igual que acontece en las cuestiones de inconstitucionalidad, la exposición de una duda razonable, pero lo que de nosotros se solicita no es un razonamiento que la resuelva sino una decisión vinculante. Por ello y aun cuando este procedimiento no haya de poseer necesariamente naturaleza contenciosa, no por dicha circunstancia se ve alterada la posición del Tribunal como intérprete supremo de la Constitución. (...) en cualquier caso, bien la resolución emanada de este Tribunal confirme la constitucionalidad de la norma convencional objeto de examen, bien declare, por el contrario, su contradicción con nuestra Ley Fundamental, dicha resolución posee los efectos materiales de cosa juzgada. (...) el efecto ejecutivo inmediato y directo ha de ser la reforma de la Constitución con carácter previo a la aprobación del tratado».

Obsérvese que es la norma interna fundamental la que por sí misma admite someterse a revisión, que se sustanciará conforme a los procedimientos de los artículos 167 ó 168 de la CE.

Pero, ¿qué ocurriría si por defecto de información o por otra causa cualquiera sucediese que un tratado, celebrado de conformidad con los requisitos exigidos en el derecho interno español fuese inconstitucional, ya que el Gobierno o el Parlamento pueden solicitar el dictamen del TC, pero no están obligados a hacerlo? Sería este un problema del control de constitucionalidad de los tratados que no podemos examinar con todas sus consecuencias y extensión ${ }^{18}$,

18 Para ello, véase Arroyo Lara (1987): «Consideración sobre el alcance y contenido del artículo 96.1, «in fine» de la Constitución Española», op. cit., pp. 413419; Remiro Brotóns, Antonio (1981): «La constitucionalidad de los tratados internacionales y su control por el Tribunal Constitucional», en El Tribunal Cons- 
Eladio Arroyo y Luis Pérez • La aplicación constitucional preferente...

pero aseveramos que si el dictamen del TC afirma la contradicción con un futuro tratado, pueden ocurrir al menos tres cosas: primero, que se renegocien las cláusulas del tratado incompatibles con la Constitución; segundo, que efectivamente se revise la Constitución ${ }^{19} ; \mathrm{y}$, tercero, que se haga expresa reserva de las estipulaciones pactadas, siempre que el convenio admita reservas.

Aún más, el artículo 93, que permite el traspaso del ejercicio de competencias estatales a organismos e instituciones internacionales, establece un sistema que se rige por el derecho interno: no se puede celebrar esta clase de tratados salvo mediante una Ley Orgánica, que en su caso autorizaría su celebración. Ahora bien, si se admite comúnmente que la CE es inatacable de forma directa

titucional, Madrid, Instituto de Estudios Fiscales, vol. III; Rodríguez-Zapata, Jorge (1981): «Los tratados internacionales y el control de constitucionalidad", en Tribunal Constitucional, Madrid, Instituto de Estudios Fiscales, vol. III.

19 Como así ocurrió con el Tratado de la Unión Europea firmado en Maastricht el 9 de febrero de 1992. En este caso el Gobierno decidió consultar al TC sobre la conformidad con la CE de algunas cláusulas contenidas en el Tratado, asunto que resolvió en la Declaración 1/1992, de 1 de julio de 1994 (disponible en http://www. boe.es/g/es/bases datos tc/doc.php?col e c c i o $n=$ t c \& id = D E C L A R A C I ON-1992-0001). Véase al respecto Mangas Martín, Araceli (1992): «La Declaración del Tribunal Constitucional sobre el artículo 13.2 de la Constitución (una reforma innecesaria e insuficiente)», Revista Española de Derecho Internacional 2, pp. 381-393. por normas convencionales, en tanto existe el artículo 95 para prevenir tal cosa-dejando de lado por el momento las normas provenientes de la Unión Europea, que por reiterada jurisprudencia del Tribunal de Justicia de las Comunidades Europeas y del mismo TC, priman sobre la Constitución-, no ocurre igual con el resto del ordenamiento interno.

Los trámites previos al texto constitucional, que se fundamentaban en el precedente del artículo 65 de la Constitución de diciembre de 1931, fueron absolutamente favorables a las tesis internacionalistas. En el Borrador y en el Anteproyecto -artículos 7.2 y 6.1 respectivamente-, se especificaba que, una vez publicados, los convenios internacionales válidamente celebrados tendría jerarquía superior a las leyes. La Ponencia Constitucional, sin explicación alguna, los rechazó y su redacción es la que existe en la $\mathrm{CE}^{20}$ que, sin embargo, contiene una precisión muy importante: que los tratados solo podrán ser derogados, modificados o suspendidos de acuerdo con las normas del propio tratado o del derecho internacional general.

¿Estamos ante una jerarquía implícita? Creemos que la respuesta debe ser afirmativa. Si las normas de un tratado, válido y aplicable, no pueden ser suspendidas, modificadas o derogadas por otra ley interna, quiere decir que su aplicabilidad es superior a aquella

20 Véase Serrano Alberca (1985): «Artículo 93», op. cit., pp. 1325-1328. 
de las demás normas internas: solo podrían verse afectadas si el propio tratado contiene normas para los casos previstos y de lo contrario por las de la Convención de Viena sobre el Derecho de los Tratados, de 23 de mayo de 1969 que, como ya hemos comprobado, tiene el carácter de norma fundamental de la $\mathrm{CE}^{21}$. En nuestra opinión, la cuestión de la jerarquía está fuera de dudas. Una norma interna, inatacable por las demás e incluso no susceptible de suspensión en su aplicación, es jerárquicamente superior. Por tanto, las posibles contradicciones entre normas provenientes de un

21 La adhesión de España a la Convención se efectuó el 2 de mayo de 1972, pero la entrada en vigor no se produjo hasta enero de 1980. Se publicó en el BOE el 13 de junio de 1980. Como ya señalamos, desde diciembre de 1978 hasta enero de 1980, las normas generales del derecho internacional a que se refiere el artículo 96.1 eran fundamentalmente las contenidas en la Convención de Viena sobre modificación, derogación o suspensión; al publicarse en el BOE forman parte también del Derecho interno. Sobre la aplicabilidad directa de la Convención de Viena, véase Mangas Martín, Araceli (1980): "Cuestiones de Derecho Internacional Público en la Constitución Española de 1978», Revista de la Facultad de Derecho de la Universidad Complutense 61, pp. 143-184; Remiro Brotóns, Antonio (1985): "Artículo 96. Tratados internacionales como parte del ordenamiento interno", en Comentarios a las Leyes Politicas: Constitución Española de 1978 (Alzaga dir.), Madrid, Edersa; Sánchez Rodríguez, Luis Ignacio (1984): El proceso de celebración de los tratados internacionales y su eficacia en el sistema constitucional español (teoría y práctica), Madrid, International Law Association, Sección Española. tratado y normas internas debe resolverse siempre en favor de las primeras, concediendo primacía a la aplicación de la norma creada internacionalmente ${ }^{22}$. Ello no significa que la norma interna se convierta en nula, sino que, como ocurre para la incorporación de normas internacionales en el derecho interno no son aplicables tanto las anteriores como las posteriores. Existen, claro está, pero los jueces y tribunales deben escoger, en supuestos de contradicción, las que provienen del derecho convencional. Si así no ocurriese, se produciría una derogación, modificación o suspensión de normas convencionales, lo que está taxativamente prohibido por el artículo 96.1 de la propia $\mathrm{CE}^{23}$.

A mayor abundamiento, el artículo 27 de la Convención de Viena -reiteramos, derecho interno español-, dice que «una parte no podrá invocar las disposiciones de su derecho interno como justificación del incumplimiento de un tratado [...]». Es decir, por cualquier vía que escojamos, la primacía resalta por encima de las normas internas. Todo el sistema legislativo español ha de plegar-

22 Serrano Alberca (1985) ha dicho que algunos comentaristas, «haciendo gala de ingenio, han querido encontrar en la alusión que a dicho conjunto de normas hace el artículo 96.1, no solo su constatación, sino incluso el reconocimiento de la supremacía del Derecho internacional general sobre el derecho interno.» ("Artículo 93», op. cit., pp. 1327).

23 Arroyo Lara (1987): «Consideración sobre el alcance y contenido del artículo 96.1, «in fine» de la Constitución Española», op. cit., pp. 414. 
Eladio Arroyo y Luis Pérez • La aplicación constitucional preferente...

se a las normas convencionales. Esto no porque lo afirmemos gratuitamente, sino porque la misma CE así lo determina. Varias sentencias del Tribunal Supremo, en especial de los años 1970 y 1971 afirman que la modificación de un tratado internacional por una norma interna no es factible sin la intervención de las partes que celebraron el tratado. En otras palabras, que el o los tratados no pueden ser derogados por normas internas sino por normas internacionales.

\section{OTRAS REFERENCIAS CONSTITUCIONALES}

Existe una cuestión que se aleja algo más del esquema general que hemos planteado: el artículo 93 de la CE. Este precepto se ideó -como lo expuso la Ponencia Constitucional en su momento-, para ser utilizado en el supuesto de la futura adhesión a las Comunidades Europeas ${ }^{24}$. Los Estados miembros de estas poseían normas constitucionales que daban acogida a los poderes comunitarios -como la alemana y la danesa-, reformaron y elaboraron textos constitucionales -como la griega y la española-, realizaron modificaciones especificas -como la belga y luxemburguesa-, o bien forzaron notoriamente la interpretación de los textos originales a los efectos de dar la autorización precisa -caso de Italia, en su artículo 11,

24 Así lo expresa el Consejo de Estado en el Dictamen 47.939, de 13 de julio de 1985. o de Francia- ${ }^{25}$. Este último, pese a ser Estado fundador de las Comunidades, prefirió no realizar una reforma constitucional, pues estimó de forma algo peregrina que era preferible una nueva lectura del texto constitucional y una interpretación más o menos forzada.

La CE arranca de los precedentes de estos Estados y obtuvo un texto preciso que, comparativamente, es uno de los mejor elaborados. El artículo 93 realiza una profunda transformación del sistema español general ${ }^{26}$. Para celebrar y manifestar el consentimiento en cualquier clase de tratados se requiere lo dispuesto en el artículo 94, excepto cuando la firma de un tratado implique

25 Las referencias en Serrano Alberca (1985): "Artículo 93", op. cit., pp. 1324 y 1329.

26 Véanse los estudios de Herrero de Miñón, Miguel (1992): «Constitución Española y Unión Europea: comentarios al artículo 93 de la Constitución Española», Revista de las Cortes Generales 26, pp. 7-20; Mangas Martín, Araceli (1992): «Los tratados internacionales (artículos 93 a 96 de la CE)», Revista de Derecho Político 36, pp. 419-438; Remiro Brotóns, Antonio (1985): «Comentarios a los artículos 93 y 94 de la Constitución», en Comentarios a las Leyes Políticas: Constitución Española de 1978, (Alzaga dir.), Madrid, Edersa; Rodríguez Iglesias, Gil Carlos (1985): «Problemas jurídicos de la adhesión de España a la Comunidad Europea», Cursos de Derecho Internacional de VitoriaGasteiz 1984, Vitoria, Universidad del País Vasco, pp. 191-240; Sánchez Rodríguez, Luis Ignacio (1991): «El artículo 93 CE y el bloque de la constitucionalidad: algunos problemas", en Estudios sobre la Constitución española: Homenaje al profesor Eduardo García de Enterría (Martín Retortillo coord.), Madrid, Civitas. 
"que se atribuya a una organización o institución internacional el ejercicio de competencias derivadas de la Constitución.». Este precepto, además de requerir una Ley Orgánica para la autorización, contempla expresamente un mecanismo de garantías especiales que, al parecer, los demás tratados no necesitan.

Si analizamos el texto constitucional observamos que, por razón de la materia, se transfiere el ejercicio de competencias contenidas en la Constitución sin exclusión alguna. Se produce una «cesión de ejercicio", es decir, alguien recibe, por vía convencional, nada menos que la posibilidad de ejercer competencias constitucionales. Con técnica jurídica acertada, se dice «transferencia de ejercicio", no «transferencia de competencia», precisión de la que carecen las demás Constituciones, excepto la de Luxemburgo. No es, pues, lo mismo transferir competencias, que son intransferibles puesto que son intrínsecas a la soberanía del Estado, que el ejercicio de las mismas ${ }^{27}$. El Estado, como ordenamiento, permanece plena-

27 Se equivoca Serrano Alberca (1985) cuando dice: «la característica propia de estos tratados es, por tanto, la de modificar las competencias previstas por la constitución interna al delegarlas a una organización internacional.» ("Artículo 93», op. cit., pp. 1329). También Sánchez Patrón (2005) cuando emplea expresiones como «transferencia de sus prerrogativas», «transferir competencias» o "cesión de competencias» ( «La contribución del Consejo de Estado a la aplicación del artículo 93 de la Constitución Española», op. cit., pp. 780, 781, 782, 783 у 787). mente soberano y lo que se transfiere es la acción que es inherente a cada competencia. Con la transferencia se pierde la acción, pero se conserva el derecho. Es una distinción que, agudamente, estableció la Escuela de Viena, singularmente el ya citado Verdross y que consiste en separar «soberanía» de «supremacía», único sistema capaz de explicar, por ejemplo, los arrendamientos o cesiones de utilización de parte del territorio -para bases militares, entre otros-. "Supremacía» equivaldría en derecho privado a la posesión, mientras que la «soberanía», que equivaldría a propiedad, es intransferible, todo ello entendido en términos aproximados ${ }^{28}$.

En suma, la organización destinataria de la cesión es, o va a ser, titular de la acción o ejercicio de la competencia. El tratado que contempla esa cesión debe ser especial: sus normas serán, como las de los demás, automáticamente incorporadas al derecho interno, normas self-executing, autoejecutables, y otras no, pero con dos diferencias sustancia-

28 El mismo TC dice en la Declaración 1/2004, de 13 de diciembre de 2004: «Producida la integración debe destacarse que la Constitución no es ya el marco de validez de las normas comunitarias, sino el propio Tratado cuya celebración instrumenta la operación soberana de cesión del ejercicio de competencias derivadas de aquélla, si bien la Constitución exige que el Ordenamiento aceptado como consecuencia de la cesión sea compatible con sus principios y valores básicos.» (disponible en http://www.tribunalconstitucional.es/jurisprudencia/Stc2004/ DTC2004-001.html). 
Eladio Arroyo y Luis Pérez • La aplicación constitucional preferente...

les. El contenido del tratado está especialmente garantizado, como afirma el artículo 93. Transformado en derecho interno es una especie de derecho interno extraordinario ${ }^{29}$, cuya jerarquía normativa es superior a cualquier otra norma que provenga de un convenio ordinario, y, por supuesto, de cualquier otra norma interna ${ }^{30}$. Decimos «parece ser» porque, extrañamente, el Gobierno

29 Término que acuñamos para referirnos a la especial posición que ocupan en la jerarquía normativa interna los tratados aprobados por la vía del artículo 93 de la CE.

30 Según la jurisprudencia del Tribunal de Justicia de las Comunidades Europeas la primacía se predica respecto de todas las normas constitucionales, incluidas las de rango constitucional (Sentencia de 17 de diciembre de 1970, Asunto «Internationale Handelgesellschaft», y Sentencia de 6 de mayo de 1980, Asunto "Comisión c. Bélgica»). El carácter absoluto con que se concibe la primacía en la jurisprudencia comunitaria quedó de manifiesto en la Sentencia de 9 de marzo de 1978, «Asunto Simenthal», en la que determinó que el juez nacional tiene la obligación de aplicar íntegramente el derecho comunitario y proteger los derechos que confiere a los particulares, dejando sin aplicación toda norma nacional eventualmente contraria a aquel, que sea anterior o posterior a la norma comunitaria. Por tanto, el derecho comunitario lo que hace es desplazar a la norma nacional pero no la elimina del ordenamiento, pues puede ser de aplicación a otros supuestos en los que no entra en conflicto. Las sentencias del Tribunal de Justicia de las Comunidades Europeas se encuentran disponibles en línea en http://curia.europa.eu/es/content/juris/index.htm. El mejor estudio sobre los principios del Derecho comunitario en sus relaciones con el Derecho interno es el de Mangas Martín, Araceli (1986): Dere- o las Cortes garantizan que se van a cumplir, pero cabe preguntarse si las demás normas provenientes de un tratado cualquiera no están garantizadas. Si existe incorporación automática, la misma mecánica del derecho internacional obliga a que este se cumpla, con garantía o sin ella. La única explicación plausible es que, con esta frase, la Constitución desea hurtar esta clase de tratados, los del artículo 93, a un posible recurso de inconstitucionalidad, previsto en la Ley Orgánica 2/1979, de 3 de octubre de 1979, del Tribunal Constitucional y en la misma CE. Lo que si afirmamos rotundamente es que no puede garantizarse el cumplimiento de algo que puede ser declarado intrínsecamente nulo por el TC.

De todas formas, esta parte del precepto constitucional tiene una redacción poco acertada. No es posible garantizar unos tratados y otros no, como si fuesen jerárquicamente distintos. El derecho internacional no lo reconoce así e incurriría en responsabilidad todo Estado que, firmante de un tratado que está incorporado a su derecho interno, no lo cumpliese de buena fe, lo garantice o no -lo que, además, afirma el artículo 26 de la Convención de Viena al decir que los Estados se comprometen a cumplir los tratados de buena fe. A efectos del derecho internacional, la frase del artículo 93 de la CE es irrelevante y a efectos internos también, ya que el TC, como

cho comunitario europeo y Derecho español, Madrid, Tecnos. 
está facultado por el artículo 27 de su Ley Orgánica, puede entrar a conocer de los recursos de inconstitucionalidad sobre cualquier tratado.

Sin embargo, la garantía del cumplimiento de las resoluciones emanadas de las organizaciones titulares de la cesión sí es una cuestión relevante, además de problemática y discutida ${ }^{31}$. Es el supuesto de algunas resoluciones del Consejo de Seguridad de las Naciones Unidas, de la Organización Internacional del Trabajo y, en especial, de la Unión Europea $^{32}$. La potestad normativa de la Unión Europea permite producir normas inmediatamente aplicables por los Estados miembros, tras su publicación en el Diario Oficial de la Unión. Estas resoluciones son hipotéticamente aplicables en el derecho interno español y son igualmente garantizadas. Entonces, ¿quiere ello decir que si esta expresión no constase en el artículo 93,

31 De esta cuestión nos hemos ocupado en Arroyo Lara, Eladio y Pérez Gil, Luis V. (2008): «La relación formal y material del Derecho comunitario con el Derecho Internacional Público", Anales de Derecho de la Universidad de La Laguna 25, págs. 27-37.

32 El Consejo de Estado dice en el Dictamen 984/93, de 9 de septiembre de 2003: «es cierto que el artículo 93 está específicamente concebido para las Organizaciones Internacionales a las que se haya transferido el ejercicio de competencias derivadas de la Constitución. Sin embargo, la solución que implícitamente de él se desprende en lo relativo a la adopción por el derecho interno de resoluciones emanadas de dichas Organizaciones parece que puede extenderse a los actos emitidos por otros tipos de Organizaciones Internacionales». el Gobierno, las Cortes o los tribunales podrían desechar la incorporación y aplicabilidad automáticas de las normas derivadas de la Unión Europea? Más que una regla constitucional parece una declaración programática de buenas intenciones: si el tratado de la Unión Europea dispone que ciertas resoluciones son inmediatamente aplicables de forma general en los Estados miembros y si el Estado ha prestado su consentimiento a ese tratado, las normas son directa e inmediatamente aplicables, lo garanticen o no el Gobierno o el Parlamento, incluso más allá de lo que dispone el artículo 1.5 del $\mathrm{CC}^{33}$. ¿Por qué, pues, la garantía? Pensamos que se trata de una afirmación constitucional del especial carácter del sistema comunitario. Ante los posibles recursos de las Comunidades Autónomas, cuando la Unión Europea legisle en materia de su competencia exclusiva, la garantía es un efecto ad intra frente a los poderes autónomos ${ }^{34}$; frente a la Unión Europea, la aplicabilidad de las normas es absoluta y, lógicamente, la

33 Véase Mangas Martín, Araceli (1982): «La recepción de los actos normativos de las instituciones comunitarias. El problema de su publicación", en Constitución, Comunidades Autónomas y Derecho Internacional, Santiago de Compostela, Xunta de Galicia/AEPDIRI y, todo en general, Derecho comunitario europeo y Derecho español, op. cit.

34 Asunto del que se ha ocupado el Tribunal de Justicia de las Comunidades Europeas en la Sentencia de 6 de julio de 2000, "Asunto Comisión c. Bélgica», y la Sentencia de 13 de junio de 2002, "Asunto Comisión c. España». 
Eladio Arroyo y Luis Pérez • La aplicación constitucional preferente...

forma en que el Estado reparte sus competencias es un problema que no le afec$\mathrm{ta}^{35}$. Ahora bien, obsérvese que, como es lógico, el artículo 93 no menciona expresamente ni a las Comunidades Europeas ni a la actual Unión Europea -que no podía prever en aquellos momentos-, sino que contiene una referencia genérica a cualquier organización o institución internacional, con lo que deja abierto el camino a cualquier posible cesión de ejercicio en el futuro. Este artículo faculta la transferencia de una acción competencial a una institución internacional, no necesariamente una organización intergubernamental ${ }^{36}$. Esta expresión vaga -institución- puede ser cualquier cosa, deja abierto el camino a las especulaciones que se deseen, desde una confederación o federación más o menos hipotética hasta cualquier ente de integración internacional aún no catalogado.

35 Así lo manifestaron tempranamente Fernández Flores, José Luis (1979): «La Constitución Española de 1978 y los tratados internacionales», en Estudios sobre la Constitución Española de 1978, Zaragoza, Libros Pórtico; Juste Ruiz, José (1980): «El Derecho Internacional Público en la Constitución Española de 1978», en Estudios sobre la Constitución Española de 1978, Valencia, Universidad de Valencia; Rodríguez Carrión, Antonio (1982): «La regulación de la actividad exterior de Estado en la Constitución", Revista de Derecho Político 15, pp. 95-118.

36 Por esta vía el Gobierno español prestó el consentimiento para obligarse al Estatuto de Tribunal Penal Internacional -véase la Exposición de Motivos de la Ley Orgánica 6/2000, de 4 de octubre, por la que se autoriza la ratificación de dicho Estatuto-.
La CE contiene otras referencias de interés respecto del derecho convencional, una de ellas de trascendencia internacional práctica pero que plantea algunos problemas. Nos referimos al contenido del artículo 10.2 de la CE. Y esto es importante por lo siguiente.

En primer lugar, algo tan esencial a la CE como todo el contenido relativo a la protección de los derechos fundamentales y libertades públicas ha de ser interpretado de conformidad con los textos internacionales sobre la materia ratificados por España. Es un artículo de «remisión interpretativa» y un reconocimiento explícito de la validez del derecho internacional convencional ${ }^{37}$. En este sentido, la sentencia del Tribunal Supremo de 24 de julio de 1982, al interpretar el artículo 20 de la CE en conexión con el artículo 10, hace una abierta referencia a la Declaración Universal de los Derechos Humanos de 10 de diciembre de 1948 y a los Pactos de Derechos Civiles y Políticos y de Derechos Económicos y Sociales, de 19 de diciembre de 1966, en vigor para España desde $1977^{38}$. Desde luego, no

37 El mismo TC en la Declaración 1/2004, de 13 de diciembre de 2004 ya citada dice que «es doctrina de este Tribunal que los tratados y acuerdos internacionales a los que se remite el artículo 10.2 de la Constitución constituyen valiosos criterios hermenéuticos del sentido y el alcance de los derechos y libertades que la Constitución reconoce, de suerte que habrán de tomarse en consideración para corroborar el sentido y alcance del específico derecho fundamental que ha reconocido nuestra Constitución.»

38 Repertorio de Jurisprudencia Aranzadi 4697/1982. 
es una sentencia aislada, pues tanto el Tribunal Supremo como particularmente el TC se han remitido constantemente tanto a la Declaración Universal como al Convenio Europeo de Derechos Humanos de 4 de noviembre de $1950^{39}$, a las resoluciones sobre esta materia del Consejo de Europa y a las sentencias del Tribunal Europeo de Derechos Humanos para determinar el contenido de los derechos fundamentales ${ }^{40}$.

En segundo lugar, es por tanto un reconocimiento explícito de la validez del derecho internacional convencional porque los derechos fundamentales y las libertades contenidas en la CE son, claro está, derecho interno español, pero además, hay una recepción de los Convenios internacionales sobre derechos humanos y esta es formalmente directa a través de las vías que ya hemos comentado. Así, la sentencia del Tribunal Constitucional 254/1993, de 20 de julio de 1993, reconoce expresamente el efecto directo de los convenios no publicados en materia de derechos humanos:

«(...) ante el retraso del legislador en desarrollar el artículo 18.4 de la norma fundamental sobre la protección de los ciudadanos frente a los abusos de la

39 Así, en las sentencias del Tribunal Constitucional 38/1981, de 23 de noviembre de 1981, 78/1982 de 20 de diciembre de 1982, 38/1985, de 8 de marzo de 1985.

40 Así, por ejemplo, sentencias del Tribunal Constitucional 38/1984, de 14 de marzo de 1984, 114/1984, de 29 de noviembre de 1984, 245/1991, de 16 de diciembre de 1991, 85/1994, de 14 de marzo de 1994 49/1999, de 5 de abril de 1999. informática, el artículo 18 del Convenio 108 del Consejo de Europa para la protección de las personas con respecto al tratamiento automatizado de datos de carácter personal, hecho en Estrasburgo el 28 de enero de 1981 y ratificado en España en 1984, es suficiente para reconocer el derecho a obtener información y desarrollar un derecho fundamental reconocido en la norma fundamental.»

Esto significa que los derechos humanos disfrutan de un plus de protección, primero, porque son parte de la CE, tanto en el mismo texto como a través de los tratados ratificados que forman parte del derecho interno y, segundo, los tratados se convierten, además, en una «fuente de interpretación obligatoria» o guía interpretativa sine qua non para los tribunales internos.

\section{Biobliografía}

Arroyo Lara, Eladio (1987): «Consideración sobre el alcance y contenido del artículo 96.1, «in fine» de la Constitución Española», Revista Española de Derecho Internacional 2, págs. 405-421.

Arroyo Lara, Eladio y Luis V. Pérez Gil, (2008): «La relación formal y material del Derecho comunitario con el Derecho Internacional Público", Anales de Derecho de la Universidad de La Laguna 25, págs. 27-37.

Fernández Flores, José Luis (1979): «La Constitución Española de 1978 y los tratados internacionales", en Estudios sobre la Constitución Española de 1978, Zaragoza, Libros Pórtico.

García Morillo, Joaquín (1985): El control parlamentario del gobierno en el ordenamiento español, Madrid, Congreso de los Diputados. 
Eladio Arroyo y Luis Pérez • La aplicación constitucional preferente...

González Campos, Julio (1977): «Artículo 1.5 del nuevo Título Preliminar del Código Civil», en Comentarios a las reformas del Código Civil, Madrid, Tecnos, vol. I.

Herrero de Miñón, Miguel (1992): «Constitución Española y Unión Europea: comentarios al artículo 93 de la Constitución Española», Revista de las Cortes Generales 26, págs. 7-20.

Juste Ruiz, José (1980): «El Derecho Internacional Público en la Constitución Española de 1978», en Estudios sobre la Constitución Española de 1978, Valencia, Universidad de Valencia.

Mangas Martín, Araceli (1980): «Cuestiones de Derecho Internacional Público en la Constitución Española de 1978", Revista de la Facultad de Derecho de la Universidad Complutense 61, págs. 143-184.

(1982): «La recepción de los actos normativos de las instituciones comunitarias. El problema de su publicación», en Constitución, Comunidades Autónomas y Derecho Internacional, Santiago de Compostela, Xunta de Galicia/AEPDIRI.

- (1986): Derecho comunitario europeo y Derecho español, Madrid, Tecnos.

(1992): «La Declaración del Tribu-

nal Constitucional sobre el artículo 13.2 de la Constitución (una reforma innecesaria e insuficiente)", Revista Española de Derecho Internacional 2, págs. 381-393.

(1992): «Los tratados internacionales (artículos 93 a 96 de la CE)», Revista de Derecho Político 36, págs. 419-438.

Marín López, Antonio (1952): «El problemas de las relaciones entre el Derecho interno y el Derecho internacional en las Constituciones", Revista Española de Derecho Internacional 1, págs. 529-60.

Miaja de la Muela, Adolfo (1968): Introducción al Derecho Internacional Público, Madrid, Internacional Ediciones Atlas ( $4^{\text {a }}$ ed.).

Montero Gibert, José Ramón y Joaquín García Morillo (1984): El control parlamentario, Tecnos.

Pastor Ridruejo, José Antonio (2007): Curso de Derecho Internacional Público y
Organizaciones Internacionales, Madrid, Tecnos ( $11^{\mathrm{a}}$ ed.).

Pérez Gil, Luis V. (2001): «Análisis de los principios constitucionales y las competencias en las relaciones exteriores en la Constitución española de diciembre de 1931», Revista Española de Derecho Constitucional 63, págs. 129-165.

Remiro Brotóns, Antonio (1980): «La actuación parlamentaria en la conclusión de los tratados: el problema de la calificación", Revista Española de Derecho Internacional 1/3, pp. 123-142.

(1981): «La constitucionalidad de los tratados internacionales y su control por el Tribunal Constitucional», en $E l$ Tribunal Constitucional, Madrid, Instituto de Estudios Fiscales, vol. III.

(1985): «Artículo 96. Tratados internacionales como parte del ordenamiento interno", en Comentarios a las Leyes Politicas: Constitución Española de 1978 (Alzaga dir.), Madrid, Edersa.

(1985): «Comentarios a los artículos 93 y 94 de la Constitución», en Comentarios a las Leyes Políticas: Constitución Española de 1978, (Alzaga dir.), Madrid, Edersa.

(1988): Política exterior de defensa y control parlamentario, Madrid, Centro de Estudios Constitucionales.

Rodríguez Carrión, Antonio (1982): «La regulación de la actividad exterior de Estado en la Constitución", Revista de Derecho Político 15, pp. 95-118.

Rodríguez Iglesias, Gil Carlos (1985): «Problemas jurídicos de la adhesión de España a la Comunidad Europea», Cursos de Derecho Internacional de Vitoria-Gasteiz 1984, Vitoria, Universidad del País Vasco, pp. 191-240.

Rodríguez-Zapata, Jorge (1981): «Los tratados internacionales y el control de constitucionalidad», en Tribunal Constitucional, Madrid, Instituto de Estudios Fiscales, vol. III.

Sánchez Patrón, José Manuel (2005): «La contribución del Consejo de Estado a la aplicación del artículo 93 de la Constitu- 
ción Española», en Presente y futuro de la Constitución Española de 1978, Valencia, Universitat de Valencia/Tirant lo Blanch, pp. 777-787.

Sánchez Rodríguez, Luis Ignacio (1984): El proceso de celebración de los tratados internacionales y su eficacia en el sistema constitucional español (teoría y práctica), Madrid, International Law Association, Sección Española.

Sánchez Rodríguez, Luis Ignacio (1991): «El artículo 93 CE y el bloque de la constitucionalidad: algunos problemas», en
Estudios sobre la Constitución española: Homenaje al profesor Eduardo García de Enterría (Martín Retortillo coord.), Madrid, Civitas.

Serrano Alberca, José Manuel (1985): «Artículo 93», en Garrido Falla, F. y otro: Comentarios a la Constitución, Madrid, Civitas, pp. 1324-1332.

Suy, Eric (1962): Les actes juridiques unilatéraux en Droit international public, París, R. Pichon et R. Durand-Auzias.

Verdross, Alfred (1974): Derecho Internacional Público, Madrid, Aguilar (5 ${ }^{\mathrm{a}}$ ed.). 